\title{
Effectiveness of fixed ratio punishment and durability of its effects'
}

\author{
LOWELL H. STORMS AND GEORGE BOROCZI \\ NEUROPSYCHIATRIC INSTITUTE, UNIVERSITY OF CALIFORNIA, LOS ANGELES
}

Hooded rats pressing a bar for food reward on a fixed interval schedule were shocked after every $1,2,4$, or $8 \mathrm{re}$ sponses with .6 ma shocks of $.25, .50$, or $1.0 \mathrm{sec}$. duration. All $S$ s eventually ceased responding. In retest sessions two weeks later, several $S s$ who had received the least frequent punishment were among those who did not resume bar pressing. Only for the shorter shock durations was partial punishment less effective than punishment for every response.

When punishment is used as a disciplinary technique, it is often impossible to punish every occurrence of the response to be suppressed. It has been demonstrated that punishment is a highly effective means of controlling behavior (Church, 1963; Solomon, 1964), but the studies leading to this conclusion have involved punishment of every response until cessation of responding. In the few studies dealing with partial punishment (Azrin, 1956; Dardano \& Sauerbrunn, 1964), there was no attempt to continue punishment until responding ceased. However, one study of conditioned suppression (Geller, 1964) found that a light which had been paired with shock $50 \%$ of the time could completely suppress a food rewarded response in goldfish, although such suppression extinguished more easily than suppression resulting from $100 \%$ light-shock pairings. The present experiment was conducted to investigate (a) whether partial punishment can produce complete suppression of a food rewarded response, (b) whether such suppression will endure for two weeks and through later retest sessions with food but no punishment available, (c) whether higher ratios of responses to punishments are associated with reduced effectiveness of punishment, (d) whether punishment duration influences partial punishment effects. Method

Forty-eight Long Evans male rats (Marland Breeding Farms), all approximately 100 days old, served as Ss in the experiment.

The apparatus consisted of six identical Davis Skinner boxes, each equipped with a food magazine, a feeding dish, and a grid floor. Pressing of the lever delivered a .05-gm spherical pellet according to the reinforcement schedule. Electric shocks supplied by a shocker and grid-scrambler apparatus were delivered through the grid floor of the boxes.

The procedure was similar to the procedure described by Boroczi, Storms, \& Broen (1964). Prior to the beginning of the experiment, the animals were handled daily and maintained on a 1-hr. daily feeding schedule for a period of seven days. They were then trained to press the bar to obtain pellets. Over the following two daily 1-hr. sessions at 23-hr. food deprivation, the reinforcement schedule was gradually lengthened from continuous to a 2-min. Fixed Interval (FI) schedule. Prior to punishment there were six 1-hr. daily sessions with the 2-min. FI reinforcement schedule. Following each session the Ss were given as much mashed Purina rat food as they could consume in $1 \mathrm{hr}$. in their individual cages, where water was continually available.

Punishment contingent upon bar pressing was introduced in the form of .6-ma intensity electric shocks. The Ss were randomly divided into four groups of 12 animals each. The administration of shocks was varied by using four fixed ratio schedules, each $\mathrm{S}$ receiving shocks for every single, every second, every fourth or every eighth bar press, according to S's assignment to one of the four groups. Each shock ratio group was further subdivided into three groups of four Ss, each group receiving $.25, .50$, or 1.0 sec. shocks. During the punishment sessions the 2-min. FI food reinforcement schedule was effective.

Punishment of the bar pressing response was continued until no bar pressing occurred during a full l-hr., daily session. Once the criterion of cessation was reached, the animals were returned to their individual cages for a period of 14 days, during which the 1-hr. per day feeding schedule was continued. Following this period of rest, the Ss were retested on three successive days, $1 \mathrm{hr}$. each day, under 23-hr. food deprivation, with the 2-min. FI reinforcement schedule in effect but with no punishment for responding. Results

In terms of rate of responding during the last session prior to punishment, there were no statistically significant differences among the groups assigned to the various conditions. In an analysis of variance $F=1.69$ ( $d f=3 / 36, p>.05$ ) for the groups assigned to different shock ratios, while duration and interaction comparisons both resulted in $\mathrm{F}<1$.

Punishment led to eventual cessation of bar pressing in all Ss. As in previous studies in this series (Boroczi, Storms, \& Broen, 1964; Storms, Boroczi, \& Broen, $1963,1965)$, with longer shock durations, fewer shocks were required to bring about cessation of responding $(F=8.64$, $d f=2 / 36, p<.01)$ and fewer responses occurred before cessation $(\mathrm{F}=7.14, \mathrm{df}=2 / 36, \mathrm{p}<.01)$. There was no difference in number of punishments to cessation for the different punishment ratios $(F=1.36$, $d f=3 / 36, p>.05$ ), except for the .25 sec. shock duration, where the two higher ratios required significantly more punishment than the lower ratios to produce cessation 
Table 1. Mean number of shocks required to produce cessation of responding for different shock ratios and durations.

\begin{tabular}{cccc} 
Shock Ratio & \multicolumn{3}{c}{$\begin{array}{c}\text { Shock Duration } \\
.50 \text { sec. }\end{array}$} \\
\hline $1: 1$ & .25 sec. & 1.0 sec. \\
$1: 2$ & 8.25 & 7.50 & 5.25 \\
$1: 4$ & 9.75 & 5.50 & 4.50 \\
$1: 8$ & 15.50 & 9.25 & 4.00 \\
\hline
\end{tabular}

of responding $(t=1.97, \mathrm{df}=14, \mathrm{p}<.05$, one tailed test). These results are presented in Table 1 . Since higher ratios by definition mean more responses per punishment, the number of responses to cessation was significantly higher for the higher ratios of responses to shocks $(F=12.28, \mathrm{df}=3 / 36, \mathrm{p}<.001)$.

For the analysis of the recovery data, a score of 1 or 0 was assigned to each $S$ for each session of retest according to whether or not the Shad resumed pressing the bar in that session. ${ }^{2}$ Neither the main effects of shock duration $(F<1)$ nor punishment ratio $(F=2.04$, $\mathrm{df}=3 / 36, p>.05$ ) were significant, and there were no significant interactions. However, an independent test of the effects of punishment ratios yielded a significant linear trend $(F=3.14$, df $=2 / 36, p<.05)$. It can be seen in Table 2 that this result is entirely due to easier recovery for the higher ratios of responses to punishments in the .25 and $.50 \mathrm{sec}$. shock duration conditions. Where shock duration had been $1.0 \mathrm{sec}$. there was no such trend. For this shock duration, recovery was at least as slow following less frequent punishment as it was for Ss who had been punished for every response. Discussion

Partial punishment produced thorough suppression of bar pressing in every $S$ in this experiment, even when only one shock was delivered for every eight responses. This is consistent with the findings of Azrin (1956), who had to set up special conditions to prevent a $.5 \mathrm{sec}$. shock delivered every $4 \mathrm{~min}$. from causing complete cessation of a food rewarded key pecking response in pigeons.

Table 2. Mean recovery score for different shock ratios and durations

\begin{tabular}{clcc} 
Shock Ratio & \multicolumn{3}{c}{ Shock Duration } \\
& .25 & .50 & 1.0 \\
\hline $1: 1$ & 1.0 & .50 & 1.50 \\
$1: 2$ & 1.0 & 1.25 & 1.75 \\
$1: 4$ & 2.75 & 1.75 & 1.75 \\
$1: 8$ & 2.75 & 2.25 & 0.75 \\
\hline
\end{tabular}

For some of the Ss, partial punishment led to fairly durable suppression of responding. For example, three of the $12 \mathrm{Ss}$ punished once for every eight responses failed to recover at any time during three days of retesting, and of the four who had received $1.0 \mathrm{sec}$. shocks, two failed to recover, one recovered on the last day of retesting, and one recovered on the second day. In a previous experiment (Boroczi et al, 1964) more intense shocks than those used in this experiment produced more effective and durable suppression of responding. Thus, it can be expected that more severe partial punishment will lead to even more durable effects.

Both recovery scores and the number of shocks needed to produce suppression were affected by punishment ratio only for the shorter shock durations. It appears that the longer the punishment, the less important it is whether the punishment is administered after every response. However, to assert with confidence that there is no difference between partial punishment with 1 sec. shocks and punishment for every response, replication with a much larger sample of Ss would be required. It would be of interest to investigate whether shocks of greater intensity also reduce the difference between the effects of partial punishment and punishment for every response.

\section{References}

Azrin, N. H. Some effects of two intermittent schedules of immediate and non-immediate punishment. J.. Psychol., 1956, 42, $3-21$.

Boroczi, G., Storms, L. H., \& Broen, W. E., Jr. Response suppression and recovery of responding at different deprivation levels as functions of intensity and duration of punishment. $J$, comp. physiol. Psychol., 1964, 58, 456-460.

Church, R. M. The varied effects of punishment on behavior. Psychol. Rev., 1963, 70, 369-402.

Dardano, J. F., \& Sauerbrunn, D. Selective punishment of fixed ratio performance. J. exp. Anal. Behav., 1964, 7, 255-260.

Geller, I. Conditioned suppression in goldfish as a function of shock reinforcement schedule. J. exp. Anal. Behav., 1964, 7. 345-349.

Solomon, R. L. Punishment. Amer. Psychologist, 1964, 19, 239253.

Storms, L. H., Boroczi, G., \& Broen, W. E., Jr. The effects of punishment as a function of strain of rat and duration of shock. J. comp. physiol. Psychol., 1963, 56, 1022-1026.

Storms, L. H., Boroczi, G., \& Broen, W. E., Jr. Recovery from punishment of bar pressing maintained on fixed and variable interval reward schedules. Psychon. Sci., 1965, 3, 289-290. Notes

1. This experiment was supported by a State of California Department of Mental Hygiene Research Grant No. R-64-2-26.2. We thank Walter Salinger for his help in carrying out this experiment. 2. Resumption of bar pressing is an all-or-none effect; see Storms, Boroczi, \& Broen (1963). 